\title{
Declining incidence of episodes of asthma: a study of trends in new episodes presenting to general practitioners in the period 1989-98
}

\author{
D M Fleming, R Sunderland, K W Cross, A M Ross
}

\begin{abstract}
Background-A study was undertaken to determine trends in the incidence of new episodes of asthma presented to general practitioners participating in the Weekly Returns Service of the Royal College of General Practitioners, comprising 92 practices with a registered population of approximately 680000 persons well distributed throughout England and Wales. These practices monitor the morbidity presented at every consultation, distinguishing between new episodes of illness and ongoing consultations.

Methods-Age specific weekly rates of new episodes of asthma (and of acute bronchitis) presenting to the general practitioners over the years 1989-98 were examined in four week blocks and analysed by multiple regression, separating secular from seasonal trends.

Results-Quadratic trends in episodes of asthma were evident in each of the age groups with peaks in 1993/4. Corresponding analyses for acute bronchitis disclosed similar trends generally peaking in the winter of 1993/4. Mean weekly incidence data (all ages combined) decreased in all quarters since 1993. Regional analysis (North/Central/South) showed similar decreases.

Conclusions-There has been a gradual decrease in the incidence of asthma episodes and of acute bronchitis presenting to general practitioners since 1993. The trend of an increase before 1993 followed by a decrease cannot be explained by changes in the patterns of health care usage or diagnostic preference of doctors.
\end{abstract}

(Thorax 2000;55:657-661)

Keywords: asthma; acute bronchitis; seasonality; general practice

Children's Hospital,

Steelhouse Lane,

Birmingham B4 6NH,

UK

R Sunderland

Correspondence to: Dr D M Fleming

email:

DFleming@rcgp-bru.demon. co.uk

Received 13 August 1999 Returned to authors
27 October 1999

Revised version received

2 May 2000

Accepted for publication

17 May 2000 because of lack of consistent objective data. Sears reviewed the evidence for increasing prevalence of childhood asthma and concluded that "no study has shown a decrease in prevalence over time". ${ }^{9}$ We found three studies ${ }^{10-12}$ showing decreased numbers of admissions to hospital for asthma and these findings gave rise to speculation that more asthma attacks were treated in primary care. There is a dearth of publications describing what has been happening to asthmatics since 1994.

Sears ${ }^{9}$ outlined some of the difficulties in epidemiological studies of asthma: there is no satisfactory definition; respiratory function is not always measured; asthma in some people may involve long periods of intermission; comparisons between questionnaire surveys are
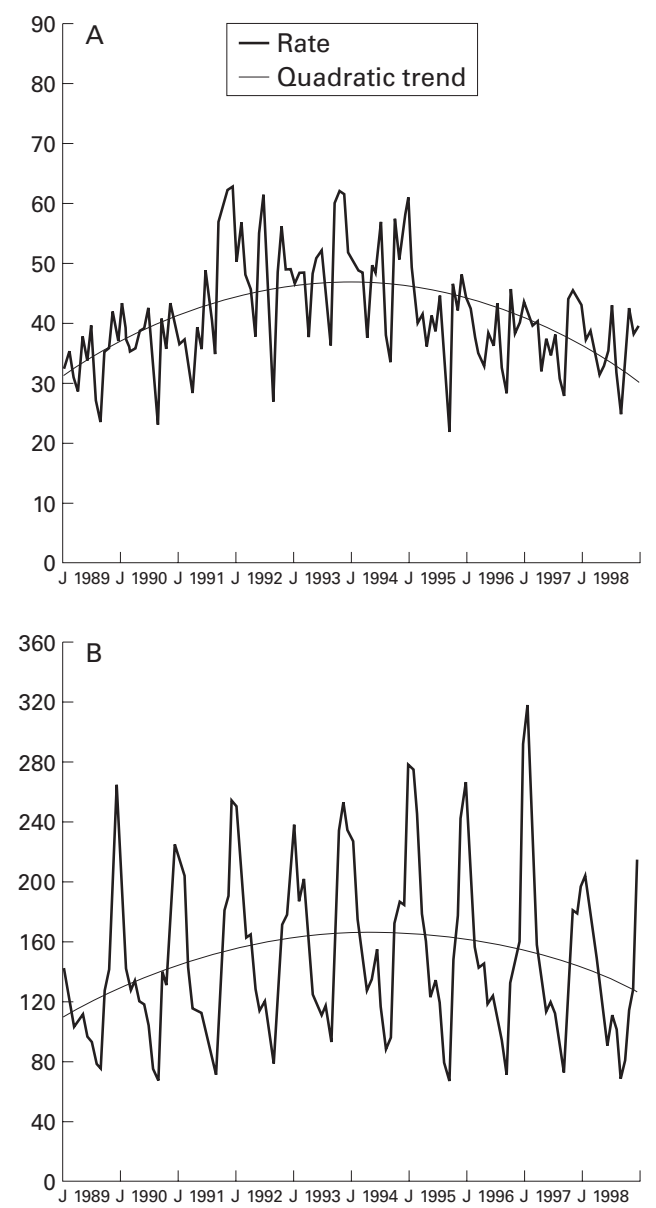

Figure 1 Mean weekly episodes per 100000 persons in four week periods, 1989-98. Modelled deseasonalised trends superimposed (note scale difference between conditions). (A) Asthma (all ages); (B) acute bronchitis (all ages). $\mathcal{f}=$ Fanuary. 

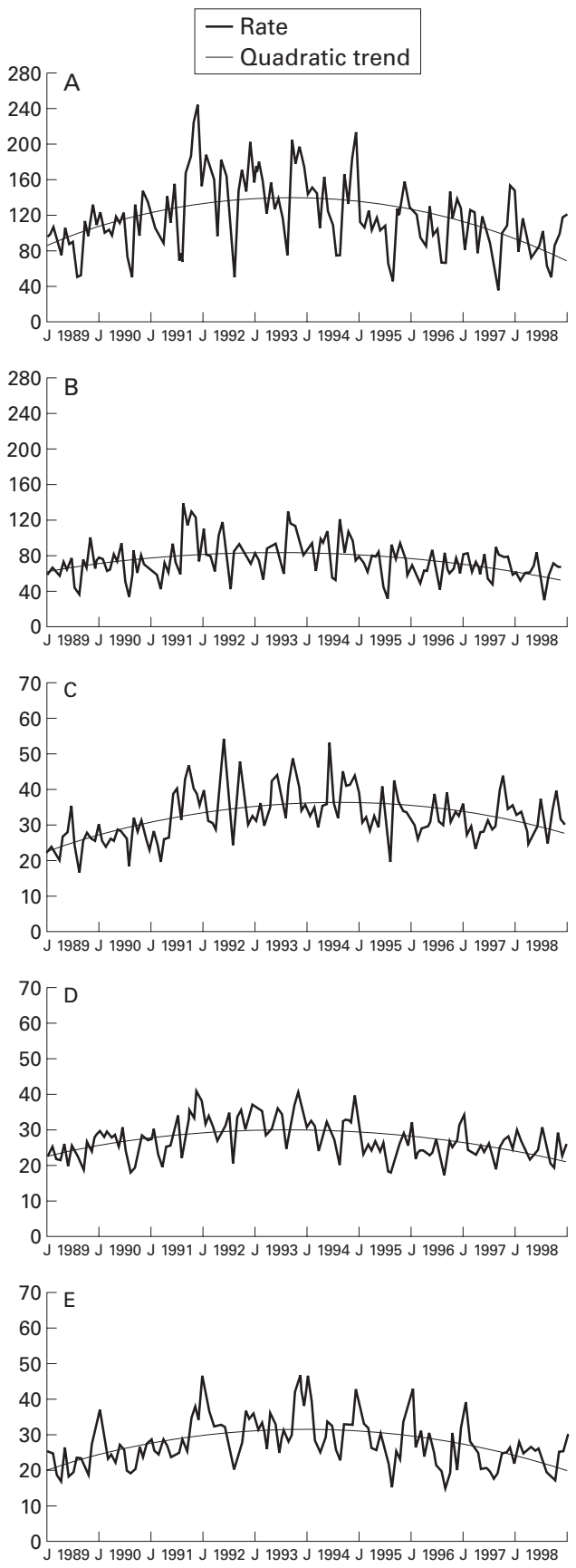

Figure 2 Age specific mean weekly asthma episodes per 100000 persons in four week periods, 1989-98. Modelled deseasonalised trends superimposed (note scale difference between age groups). (A) 0-4 years; (B) 5-14 years; (C) 15-44 years; (D) 45-64 years; (E) 65 years and over. $\mathcal{F}=$ fanuary.

difficult if different questions are posed. Other factors particularly relevant to studies in adults relate to changing patterns of health care usage (especially in hospital admission policies), changes in preferred diagnostic terms, the reclassification of asthma in the 9th revision of the International Classification of Diseases (1977), and the lack of reliable denominators for deriving age specific rates.

We here report a study of recent trends in the incidence of new episodes of asthma and of acute bronchitis using data from the Weekly Returns Service (WRS) of the Royal College of General Practitioners. ${ }^{13}$ The database has been
Table 1 Results of regression analysis of the deseasonalised age specific rates for asthma episodes (and for acute bronchitis at all ages)

\begin{tabular}{|c|c|c|c|c|}
\hline $\begin{array}{l}\text { Age group } \\
\text { (years) }\end{array}$ & $\begin{array}{l}\text { Linear and } \\
\text { quadratic } \\
\text { coefficients }\end{array}$ & Estimate $^{\star}$ & $S E$ & $\begin{array}{l}\text { Peak month of } \\
\text { fitted curve }\end{array}$ \\
\hline \multicolumn{5}{|l|}{ Asthma } \\
\hline \multirow[t]{2}{*}{$0-4$} & Time & 1.717 & 0.2073 & August 1993 \\
\hline & Time $^{2}$ & -0.0143 & 0.0015 & \\
\hline \multirow[t]{2}{*}{$5-14$} & Time & 0.746 & 0.1214 & July 1993 \\
\hline & Time $^{2}$ & 0.0063 & 0.0009 & \\
\hline \multirow[t]{2}{*}{$15-44$} & Time & 0.377 & 0.0405 & July 1994 \\
\hline & Time $^{2}$ & 0.0026 & 0.0003 & \\
\hline \multirow[t]{2}{*}{$45-64$} & Time & 0.224 & 0.0344 & August 1993 \\
\hline & Time $^{2}$ & 0.0019 & 0.0003 & \\
\hline \multirow[t]{2}{*}{$65+$} & Time & 0.335 & 0.0388 & November 1993 \\
\hline & Time $^{2}$ & 0.0026 & 0.0003 & \\
\hline \multirow[t]{2}{*}{ All ages } & Time & 0.486 & 0.0493 & November 1993 \\
\hline & Time $^{2}$ & 0.0038 & 0.0004 & \\
\hline \multicolumn{5}{|c|}{ Acute bronchitis } \\
\hline \multirow[t]{2}{*}{ All ages } & Time & 1.586 & 0.2179 & May 1994 \\
\hline & Time $^{2}$ & -0.0113 & 0.0016 & \\
\hline
\end{tabular}

^All regression coefficients were highly significant $(\mathrm{p}<0.0001)$. used previously to report increasing trends in episodes of acute asthma and of acute bronchitis between 1976 and $1987 .{ }^{4}$ At the mid point of the study there were approximately 92 practices covering a population of 680000 subjects, well distributed throughout England and Wales, reporting on the morbidity problem at each consultation and differentiating new episodes of illness from ongoing consultations.

\section{Methods}

New episodes of asthma (ICD9, code 493) recorded in the WRS were collected each week in five age groups $(0-4,5-14,15-44,45-64$, and 65 years and over), together with the populations registered. For asthma, a new episode occurs when a patient consults with a new attack or exacerbation of asthma. Consultations for review or repeat medication are not included.

Weekly data recorded over the 520 weeks between January 1989 and December 1998 were examined. (In years which included a week 53, data for weeks 52 and 53 were averaged.) The data were aggregated into 130 four week blocks and age specific episode rates (per 100000 population) were calculated. Preliminary examination of these time series suggested curvilinear secular trends and seasonal variations. For each age group in turn the four weekly episode rate was therefore regressed against "time (1-130)" and "time squared" and a dummy variable was allocated to each of the 13 four week blocks to control for seasonal variation.

We also averaged the weekly incidence data in each quarter by year over the 10 year period. Finally, we examined data by region and year. Region is defined by lines linking Liverpool and Hull (North from Central), and linking Bristol and Ipswich (Central from South). All rates presented in this paper are expressed as mean weekly rates per 100000 population.

Incidence data for new episodes of acute bronchitis (ICD9, code 466 acute bronchitis and bronchiolitis; code 490 bronchitis not specified as acute or chronic) were examined similarly and the results used to consider issues of diagnostic preference. The terms "acute 


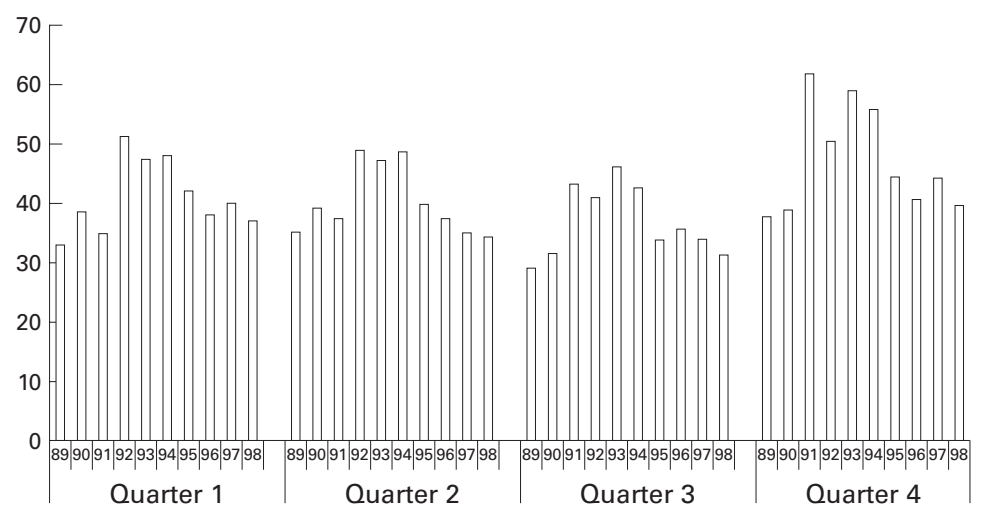

Figure 3 Asthma: mean weekly episodes per 100000 persons of all ages by quarter, 1989-98.

bronchitis" (or simply "bronchitis") are used in general practice to describe an acute illness in which wheeze is a prominent symptom and in which rales are present on auscultation. It is the diagnostic rubric in which there is greatest potential for confusion with new episodes of asthma. "Chronic bronchitis" is a term usually assigned on a single occasion and, being a chronic rather than intermittent condition, does not give rise to new episodes.

\section{Results}

The mean weekly episode rate for asthma (all ages) in each of the four week blocks is shown in fig 1. A regular seasonal pattern is evident, together with an underlying quadratic trend, which was fitted by regression analysis after controlling for seasonal variation. The resulting curve peaked in November 1993. A similar analysis of mean weekly episode rates for acute bronchitis (all ages) also resulted in a quadratic trend with a peak in May 1994.

Corresponding results of applying the same methods to the asthma data by age group are shown in fig 2. Quadratic trends were evident in each of the age groups and the results of the regression analyses are given in table 1 . The "time" and "time squared" coefficients in the regression equations were all significant at the 0.001 level, and the fitted curves had peaks ranging between July 1993 and July 1994. For each age group the hypothesis that the inclusion of the "time squared" term did not improve the explanatory power of the

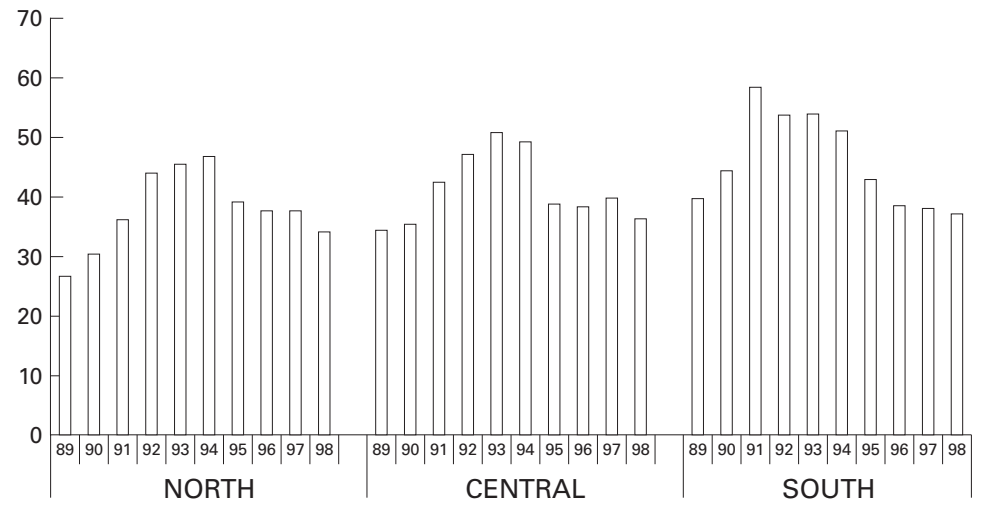

Figure 4 Asthma: mean weekly episodes per 100000 persons of all ages by regions, 1989-98. regression model was tested by calculation of the appropriate $\mathrm{F}$ statistic. In each case the null hypothesis was overwhelmingly rejected. For example, the minimum $\mathrm{F}$ statistic (for age group 5-14 years) was 49.2; the critical value at the $1 \%$ level of significance is 6.8 .

The mean weekly episode rates of asthma in each quarter by year are presented as histograms in fig 3); for each quarter the rate decreased from a peak value in 1993 or 1994 . Quarterly data for acute bronchitis (not presented) also showed decreasing trends. Regional data for asthma are shown in fig 4; similar decreases were evident in each region since 1993 or 1994.

\section{Discussion}

SECULAR TRENDS

New episodes of asthma reported to general practitioners increased between 1989 and 1993, and have since declined. The patterns of increase followed by reduction since 1993 or 1994 were evident in all age groups, in the data for each quarter of the year, and in each region. The trends for acute bronchitis were similar to those for asthma (all ages), although the bronchitis peaks in individual age groups occurred a few months later. We also examined trends in all respiratory infections combined which also peaked in 1993 or 1994. However, when addressing the issue of diagnostic preference, we considered acute bronchitis was the most likely true diagnostic competitor. In children episodes of acute bronchitis comprise about $13 \%$ of all respiratory infections, in adults $21 \%$, and in the elderly $50 \% .^{14}$

The literature on the incidence of asthma is dominated by evidence of increase. The increasing episode rates reported by general practitioners between 1989 and 1993 reported here provide further evidence of an increase in that period. The important new information concerns the evidence of a decrease since 1993 which is matched by decreasing rates for acute bronchitis.

STRENGTHS OF THE WEEKLY RETURNS SERVICE By virtue of its setting, this study has some particularly robust features which address many of the limitations outlined by Sears. ${ }^{9}$ It is based on continuous surveillance over a 10 year period (1989-98). The reporting network has been stable since 1992 with few changes in its composition of practices, general practitioners, their locations, and registered populations. The discipline of recording from every consultation minimised bias associated with selective entry of information. Data for asthma episodes reported in the network show the same seasonal trends as hospital episode data. ${ }^{14}$ Episode data for respiratory illness in the elderly have been shown to be very highly correlated with mortality data in time series analyses. ${ }^{15}$ Internal consistency of data collection in the three regions has been demonstrated. ${ }^{16}$ The information system has also been used to monitor infectious diseases, ${ }^{17}$ to investigate the effects of pollution, ${ }^{18}$ and to examine the impact of different pollens on allergic rhinitis. ${ }^{19}$ 
Finally, it is easier to maintain follow up of patients in general practice than in hospital. ${ }^{20}$

Confidence in the findings of this study is enhanced by the size of the database and the frequency of recording from the same population and doctors, giving very large numbers of repeated measurements. The comparative analysis for acute bronchitis shows that the trends for asthma are not confused because of diagnostic transfer to or from acute bronchitis. A previous study involving many of the same practices recording in a similar way was one of the earliest UK studies to draw attention to increased numbers of persons with asthma. ${ }^{3}$

INTERPRETATION

Explanation of the findings for asthma must address both the increasing and decreasing trends, and the similar findings for acute bronchitis. These will be considered under five headings previously used by Hyndman et $a l^{6}$ and Garrett et al. ${ }^{10}$

\section{Prevalence}

These data are concerned with episodes and not with persons. The number of new episodes is less than the total number of persons in any given period. In the fourth national morbidity survey (based on 468000 person years and data collected in 60 practices, 52 of which remain in the WRS), for every 10 persons (all ages) reported with asthma there were seven new episodes and 22 consultations; in the group aged $0-4$ years there were 10 new episodes and 24 consultations for every 10 persons. ${ }^{21}$ It is unlikely that changes in episode rates could have occurred without changes in prevalence.

Severity

A decrease in asthma attacks prompting consultation must suggest reduced severity. We concur with the comments of Garrett et $a l^{10}$ and of others linking severity with the risk of hospital admission and, by the same token, the likelihood of consultation with asthma attacks in general practice. Mortality from asthma has been declining since the late $1980 \mathrm{~s} .{ }^{22}{ }^{23}$ Rates of hospital admission in both adults and children showed some evidence of stabilisation in the early 1990s although admission rates in adults were higher in 1993 than in $1992 .{ }^{24}$ All these facts point to reducing severity of asthma.

Access to health care

In the UK access to health care is largely through general practitioners. Small changes in the arrangements for delivering care and following patients influences the interpretation of indicators based on health care utilisation data. Strachan and Anderson ${ }^{25}$ recognised that the trends in hospital admission may simply reflect trends in hospital utilisation. Garrett et al thought that decreasing admissions in New Zealand might be explained by a shift towards primary care. ${ }^{10}$ In England and Wales relatively few asthmatic patients are referred to hospital in any one year. ${ }^{3}$

Among recent changes in the organisation of primary care in the United Kingdom, the introduction of asthma clinics in practices and new arrangements for the delivery of out of hours care are relevant. Asthma clinics staffed by practice nurses increased nationally in the early 1990s, largely focusing on therapeutic compliance. McCowan et $a l^{26}$ found favourable changes in GP consulting patterns, prescriptions, and reduced hospital admissions among children with asthma when using a nurse facilitator (which disappeared on removal). These reductions were found at the same time as we now report a downward turn in the incidence of asthma. Nurses were not generally involved in treating new episodes of asthma or acute bronchitis, and the magnitude of their involvement can be overestimated. The fourth practice based Morbidity Survey (MSGP4) conducted in 1991/2 showed that practice nurses undertook less than $10 \%$ of the total practice consultations for obstructive airways disease (which includes asthma) and less than 1\% of the practice consultations for acute respiratory infections. ${ }^{21}$ It is difficult to conjecture a major shift of patient management between MSGP4 and the peak of the incidence trends reported here. Nevertheless, the introduction of skilled nurses working with practice guidelines may have contributed to a decline in the number of asthma episodes prompting consultation, especially in young children. Primary care surgeries for emergency consultations were introduced in 1996, but this change in "out of hours" service provision does not coincide with the trends reported here.

\section{Medical management}

In recent years there has been an increased use of prophylactic corticosteroid inhalers. Published prescribing trends ${ }^{5} 27$ show a continuous increase in the absolute numbers of prescriptions for steroid inhalers and the relative ratio of steroids to $\beta$ agonists, both before and after the peak reported here. It is difficult to reconcile the increased use of inhaled steroids between 1989 and 1993 with increased rates of asthma episodes. However, the increasing availability of steroid and $\beta$ agonist inhalant treatments in patients' homes and, hopefully, improved counselling on how these should be used may have limited the need for patients to consult during acute exacerbations. Improvement in therapeutic compliance over time may have reduced the responsiveness of airways to trigger factors. However, improvements in the management of individual patients with asthma are not likely to explain simultaneous improvements and reductions in the incidence of acute bronchitis, and it would be surprising if the effect was apparent in all age groups simultaneously.

\section{Drug toxicity}

There has been some concern that frequent use of inhaled $\beta$ agonists might increase the severity of asthma. ${ }^{28}{ }^{29}$ Whilst this opinion is not universally accepted, ${ }^{30} 31$ it could perhaps contribute to increased episodes during the late 1980s and early 1990s. However, episodes have declined since 1993 whereas the Prescription Pricing Authority, in commenting on 
prescribing patterns over the period 1992-6, stated that "there has been no reduction in bronchodilator usage as might have been expected following the increased use of steroids". ${ }^{27}$

\section{CONCLUSIONS}

We conclude that secular trends described here provide strong evidence that the "epidemic" of asthma has peaked. The similarity of trends for acute episodes of asthma and acute bronchitis argue strongly against diagnostic transfer. The evidence indicates that there has either been a change in the epidemiology of factors which initiate attacks of asthma or in the response of airways to these triggers. The occurrence of downward trends in asthma and bronchitis in all regions, all seasons, and all ages at nearly the same time cannot be linked to changes in factors which have previously been considered responsible for the increase in the community burden of asthma. Increased exposure to allergens, petrochemical pollution, and dietary factors did not suddenly change for the better in 1993. Winters have been less severe in recent years but most of the trends reported here were evident throughout the year. Excepting only the impact of nurse facilitators on asthma management in practices, we cannot find a temporal association with changes in treatment or health care utilisation. Since, until very recently, their role did not include the management of acute bronchitis or other respiratory infections, we consider that their contribution to the reduction of asthma episodes must be small relative to other factors yet to be identified. In particular, a decrease in the incidence of acute respiratory infections prompting consultations with general practitioners may have resulted from favourable environmental change. Whatever the reason, the implication of this downward trend is good news for people at risk of asthma.

The authors are grateful to the general practitioners and their staff who provided the incidence data on a continuing basis and to the Department of Health who funded this recording. We are also grateful to the Department for permission to publish though the views expressed in this paper are specifically those of the authors.

1 Frew AJ, Holgate ST. Oxford textbook of medicine. Oxford: Oxford University Press, 1996: 2724-5.

2 Anderson HR, Butland BK, Strachan DP. Trends in prevalence and severity of childhood asthma. BMf 1994;308: $1600-4$.

3 Fleming DM, Crombie DL. Prevalence of asthma and hay fever in England and Wales. BMF 1987;294:279-83.

4 Ayres JG, Noah ND, Fleming DM. Incidence of episodes of acute asthma and acute bronchitis in general practice 1976-1987. Br F Gen Pract 1993;43:361-4.

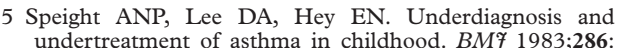
undertreatr.

6 Hyndman SJ, Williams DR, Merrill SL, et al. Rates of admission to hospital for asthma. BMf 1994;308:1596600.

7 British Thoracic Association. Deaths from asthma in two regions of England. BMF 1982;285:1251-5.

8 Magnus P, Jaakkola JJK. Secular trend in the occurrence of asthma among children and young adults: critical appraisal of repeated cross section. BMf 1997;314:1795-9.

9 Sears MR. Descriptive epidemiology of asthma. Lancet 1997;350(Suppl 1):1-4.

10 Garrett J, Kolbe J, Richards G, et al. Major reduction in asthma morbidity and continued reduction in asthma mortality in New Zealand: what lessons have been learned? Thorax 1995;50:303-11.

11 Wennergren G, Kristjansson S, Stannegard IL. Decrease in hospitalisation for treatment of childhood asthma with increased use of anti-inflammatory treatment, despite an increase in prevalence of asthma. F Allergy Clin Immunol 1996;97:742-8.

12 Stromberg L. Decreasing admissions for childhood asthma to a Swedish Country Hospital. Acta Paediatr 1996;85:1736.

13 Fleming DM. Weekly Returns Service of the Royal College of General Practitioners. Community Dis Public Health 1999;2:96-100.

14 Lung and Asthma Information Agency. Seasonal variations in asthma. Factsheet 93/4. London: Department of Public Health Sciences, 1993.

15 Fleming DM, Cross KW, Crombie DL, et al. Respiratory illness mortality in England and Wales. Eur 7 Epidemiol 1993;9:571-6

16 Ross AM, Corden JM, Fleming DM. The role of oak pollen in hay fever consultations in general practice and the factors influencing patients' decision to consult. $\mathrm{Br} \mathcal{F}$ Gen Pract 1986;46:451-5.

17 Fleming DM, Crombie DL, Norbury CA. Observations on the influenza epidemic November/December 1989. Br f Gen Pract 1990;40:495-7.

18 Ayres J, Fleming D, Williams M, et al. Measurement of respiratory morbidity in general practice in the United Kingdom during the acid transport event of January 1985. Environ Health Perspect 1989;79:83-8.

19 Ross AM, Fleming DM. Incidence of allergic rhinitis in general practice 1981-92. BMF 1994;308:897-900

20 Blair H. Natural history of childhood asthma: 20 year follow-up. Arch Dis Child 1977;52:613-9.

21 McCormick A, Fleming D, Charlton J. Morbidity statistics from general practice. 4th national study 1991-2. Series MB5, No.3. A study carried out by the Royal College of General Practitioners, the Office of Population Censuses and Surveys, and the Department of Health. London: HMSO, 1995.

22 Department of Health. Asthma: an epidemiological overview. Central Health Monitoring Unit Epidemiological Overview Series. London: HMSO, 1995.

23 Campbell MJ, Cogman GR, Holgate ST, et al. Age specific trends in asthma mortality in England and Wales 1983-95: results of an observational study. BMF 1997;314:1439-41.

24 Lung and Asthma Information Agency. Trends in hospital admissions for asthma. Factsheet 96/2. London: St George's Hospital Medical School, 1996.

25 Strachan DP, Anderson HB. Trends in hospital admission rate for asthma in children. BMF 1992;304:819-20

26 McCowan C, Neville RG, Crombie IK, et al. The facilitator effect: results from a 4 year follow-up of children with asthma. Br f Gen Pract 1997;47:156-60.

27 Prescription Pricing Authority. Annual report 1 April 1996-31 March 1997

28 Crane J, Burgess C, Pearce NB, et al. The beta-agonist controversy, a perspective. Eur Respir Rev 1993;3:475-82.

29 Suissa S, Blair L, Ernst P. Patterns of increasing beta-agonist use and the risk of fatal or near-fatal asthma. Eur Respir $\mathcal{F}$ 1994;9:1602-9.

30 Garrett JE, Lanes SF, Kolbe J, et al. Risk of severe life threatening asthma and beta-agonist type: an example of confounding by severity. Thorax 1996;51:1093-9.

$31 \mathrm{McF}$ adden ER Jr. The beta2-agonist controversy revisited. Ann Allergy Asthma Immunol 1995;75:173-6. 